\title{
Effects of nitric oxide synthase inhibition on glutamine action in a bacterial translocation model
}

\author{
Rosana G. C. Santos ${ }^{1}$, Iara E. P. Quirino ${ }^{1}$, Mirelle L. Viana ${ }^{1}$, Simone V. Generoso ${ }^{2}$, Jacques R. Nicoli ${ }^{3}$, \\ Flaviano S. Martins ${ }^{3}$, José A. Nogueira-Machado ${ }^{4}$, Rosa M. E. Arantes ${ }^{5}$, Maria I. T. D. Correia ${ }^{6}$ \\ and Valbert N. Cardoso ${ }^{1 *}$ \\ ${ }^{1}$ Universidade Federal de Minas Gerais, School of Pharmacy, 4th Floor/4144, Antônio Carlos Avenue, \\ 6627 Pampulha, Belo Horizonte, MG 31270-901, Brazil \\ ${ }^{2}$ Universidade Federal de Minas Gerais, School of Nursing, Nutrition Department, 2nd Floor/200, \\ Alfredo Balena Avenue, 190 Santa Efigênia, Belo Horizonte, MG 30130-100, Brazil \\ ${ }^{3}$ Universidade Federal de Minas Gerais, Institute of Biological Science, PO Box 486, 4th Floor/J 171, \\ Antônio Carlos Avenue, 6627 Pampulha, Belo Horizonte, MG 31270-901, Brazil
}

${ }^{4}$ Instituto de Ensino e Pesquisa Santa Casa BH, Francisco Sales Avenue, 1.111, 9th Floor/"D", Santa Efigênia,

Belo Horizonte, MG 30150-221, Brazil

${ }^{5}$ Universidade Federal de Minas Gerais, Institute of Biological Science, PO Box 486, 3rd Floor/C 251,

Antônio Carlos Avenue, 6627 Pampulha, Belo Horizonte, MG 31270-901, Brazil

${ }^{6}$ Universidade Federal de Minas Gerais, School of Medicine, Alfredo Balena Avenue, 190 Santa Efigênia,

Belo Horizonte, MG 30130-100, Brazil

(Submitted 18 October 2012 - Final revision received 8 May 2013 - Accepted 8 May 2013 - First published online 18 June 2013)

\section{Abstract}

Glutamine may be a precursor for NO synthesis, which may play a crucial role in bacterial translocation (BT). The goal of the present study was to investigate the potential effects of glutamine on BT and the immunological response in an experimental model of NO synthase inhibition by NG-nitro-L-arginine methyl ester (L-NAME). Mice were randomly assigned to four groups: sham; intestinal obstruction (IO); IO + $500 \mathrm{mg} / \mathrm{kg}$ per d glutamine (GLN); IO + GLN plus $10 \mathrm{mg} / \mathrm{kg}$ per d L-NAME (GLN/LN). The groups were pretreated for $7 \mathrm{~d}$. BT was induced by ileal ligation and was assessed $18 \mathrm{~h}$ later by measuring the radioactivity of ${ }^{99 \mathrm{~m}}$ Tc-Escherichia coli in the blood and organs. Mucosal damage was determined using a histological analysis. Intestinal permeability (IP) was assessed by measuring the levels of ${ }^{99 \mathrm{~m}} \mathrm{Tc}$-diethylenetriaminepentaacetic acid in the blood at 4,8 and $18 \mathrm{~h}$ after surgery. IgA and cytokine concentrations were determined by ELISA in the intestinal fluid and plasma, respectively. BT was increased in the GLN/LN and IO groups than in the GLN and sham groups. IP and intestinal mucosa structure of the sham, GLN and GLN/LN groups were similar. The GLN group had the highest levels of interferon- $\gamma$, while IL-10 and secretory IgA levels were higher than those of the IO group but similar to those of the GLN/LN group. The present results suggest that effects of the glutamine pathway on BT were mediated by NO. The latter also interferes with the proinflammatory systemic immunological response. On the other hand, IP integrity preserved by the use of glutamine is independent of NO.

Key words: Glutamine: ${ }^{99}$ Technetium: Bacterial translocation: Nitric oxide

Damage to the intestinal barrier, bacterial translocation (BT) and immunosuppression increase infection risk and mortality $^{(1)}$. Glutamine plays an important role in the regulation of the gut barrier and is fundamental for the proliferation of enterocytes ${ }^{(2)}$.

Glutamine is required for a number of specific biochemical reactions and has a broad range of metabolic functions.
This amino acid can function in the formation of nucleic acids, nucleotides and proteins or can produce glucose, glutathione, urea or NO via glutamate. NO is a pluripotent signalling molecule derived from arginine, which is one of the ultimate products of glutamine metabolism ${ }^{(3)}$. The above-mentioned pathways are integrated and determine metabolic functions.

Abbreviations: BT, bacterial translocation; cpm, counts per min; DTPA, diethylenetriaminepentaacetate; GLN, intestinal obstruction group receiving glutamine by oral administration and a specially prepared diet; GLN/LN, intestinal obstruction group receiving glutamine plus NG-nitro-L-arginine methyl ester (L-NAME) by oral administration and a specially prepared diet; HSP, heat shock protein; IO, intestinal obstruction group receiving a standard diet; IFN- $\gamma$, interferon- $\gamma$; sham, simulated group receiving a standard diet; sIgA, secretory Ig type A.

*Corresponding author: V. N. Cardoso, fax +55 3188128590 , email valbertcardoso@yahoo.com.br 
Glutamine can also exert direct effects on the immune system. The extracellular level of glutamine regulates the proliferation of $\mathrm{T}$ cells and the differentiation of $\mathrm{B}$ cells into antibodies and secreting cells. It also enhances phagocytosis and superoxide production in neutrophils and macrophages. The latter act by destroying foreign material by exposing it to free radicals and hydrolytic enzymes, by antigen presentation to T lymphocytes (in association with MHC II) and by the activation of lymphocyte subpopulations via cytokine secretion ${ }^{(4)}$.

$\mathrm{BT}$, the passage of bacteria or their products from the intestine to sterile organs, is caused by many conditions such as malnutrition, intestinal obstruction, cancer, septic states and trauma. It is harmful to the health and recovery of patients ${ }^{(5)}$. Three mechanisms are involved in BT: reduced intestinal barrier function; modified gut microbiota; inadequate response of the host immune system ${ }^{(6)}$. Intestinal permeability changes are associated with higher BT levels and sepsis ${ }^{(7)}$. Local immune response and cytokines modulate intestinal permeability and BT to avoid increased inflammation ${ }^{(8-10)}$. Thus, the host immune response plays a major role in the overall process.

Ding \& $\mathrm{Li}^{(11)}$ demonstrated that animals pretreated with glutamine displayed reduced BT and damage to the intestinal mucosa after surgical trauma and endotoxaemia compared with untreated animals. In addition, IgA levels were increased in the GLN group (intestinal obstruction group receiving glutamine by oral administration and the specially prepared diet).

$\mathrm{NO}$ is responsible for cytotoxic activity that results in oxidative stress and tissue damage; it is an important mediator of the inflammatory response $\mathrm{e}^{(12,13)}$. NO is an important intracellular and intercellular signalling molecule involved in the regulation of diverse physiological and pathophysiological mechanisms $^{(14)}$. Basal NO production maintains adequate perfusion, regulates intestinal permeability and minimises mucosal and microvascular barrier dysfunction after intestinal ischaemia $^{(15,16)}$.

Previous studies performed in our laboratory have demonstrated that glutamine reduces BT. These studies have reported positive results using $500 \mathrm{mg} / \mathrm{kg}$ per $\mathrm{d}$ of glutamine. On the other hand, the concentration of $250 \mathrm{mg} / \mathrm{kg}$ per $\mathrm{d}$ was inefficient $^{(17,18)}$. NO is probably an important metabolite of the glutamine pathway and may be involved in BT. However, the immunological aspects and role of glutamine in BT and intestinal permeability require further investigation. Thus, the goal of the present study was to investigate the effects of NO synthase inhibition after glutamine treatment on BT and intestinal mucosal integrity as well as to assess the local and systemic immune responses to NO synthase inhibition.

\section{Methods}

\section{Animals and diets}

In the present study, 6-week-old male Swiss mice weighing between 25 and $30 \mathrm{~g}$ were used. For each experiment, mice were randomly divided into four groups: (1) the sham group, with no intestinal obstruction and receiving $0.3 \mathrm{ml}$ of saline by oral administration; (2) the IO group, with intestinal obstruction and receiving $0.3 \mathrm{ml}$ of saline by oral administration; (3) the GLN group, with intestinal obstruction and receiving $0.3 \mathrm{ml}$ of glutamine $(500 \mathrm{mg} / \mathrm{kg}$ per d) (L-glutamine; Ajinomoto do Brazil) by oral administration; (4) the GLN/LN group, with intestinal obstruction and receiving $0.3 \mathrm{ml}$ of glutamine plus NG-nitro-L-arginine methyl ester (L-NAME) (10 mg/kg per d) by oral administration. The mice were orally administered glutamine for $7 \mathrm{~d}$ before the induction of intestinal obstruction and were maintained under normal conditions of daylight and darkness in individual cages with free access to water.

The mice in the sham and IO groups were fed a conventional chow diet and were orally administered a placebo (saline solution). In contrast, the GLN and GLN/LN groups received glutamine and a specially prepared diet to render them isoenergetic and isoproteic (Table 1). The study protocol was approved by the Ethics Committee for Animal Experiments at the Universidade Federal de Minas Gerais and complied with the guidelines for the care and use of laboratory animals recommended by the Institute of Laboratory Animal Resources.

\section{Glutamine solution preparation}

Glutamine was dissolved in HEPES buffer at a $\mathrm{pH}$ between $7 \cdot 4$ and $7 \cdot 6$. A solution was prepared using $10 \mathrm{mmol} / 1$ of HEPES, $145 \mathrm{mmol}$ of $\mathrm{NaCl}$ and $5 \mathrm{mmol}$ of EDTA. For complete dissolution, the glutamine and buffer were heated at $37^{\circ} \mathrm{C}$ for $5 \min ^{(17)}$.

\section{Surgical procedure}

The mice were anaesthetised intraperitoneally with xylazine $(8.7 \mathrm{mg} / \mathrm{kg})$ and ketamine $(25.2 \mathrm{mg} / \mathrm{kg})$ solutions. The abdomen was opened through a midline incision and the terminal ileum was isolated and ligated. The mice in the sham group underwent only a laparotomy ${ }^{(17,19,20)}$. The abdominal wound was closed in two layers.

\section{Escherichia coli radiolabelling}

A sample of an E. coli ATCC-10,536 culture grown overnight in trypticase agar was transferred to $10 \mathrm{ml}$ of saline solution. A bacterial culture at $10^{8}$ colony-forming units $/ \mathrm{ml}$ was adjusted spectrophotometrically to $31 \%$ transmittance at $580 \mathrm{~nm}$. A $2 \mathrm{ml}$ aliquot of the bacterial suspension was incubated with

Table 1. Diet composition*

\begin{tabular}{lcc}
\hline Macronutrients & $\begin{array}{c}\text { Standard diet } \\
(100 \mathrm{~g})\end{array}$ & $\begin{array}{c}\text { Specially prepared } \\
\text { diet }(100 \mathrm{~g})\end{array}$ \\
\hline Carbohydrates $(\mathrm{g})$ & 51.00 & 51.25 \\
Proteins $(\mathrm{g})$ & 23.00 & 22.75 \\
Lipids $(\mathrm{g})$ & 4.00 & 4.00 \\
\hline
\end{tabular}

* The standard diet Labina ${ }^{\circledR}$ was given to the simulated group (sham), and intestinal obstruction group (IO). The specially prepared diet, given to the $1 \mathrm{O}+500 \mathrm{mg} / \mathrm{kg}$ per d glutamine (GLN) and IO + GLN plus $10 \mathrm{mg} / \mathrm{kg}$ per $\mathrm{d}$ of NG-nitro-L-arginine methyl ester (L-NAME) (GLN/LN) groups, is a modified diet from Labina ${ }^{\circledR}$ to render them isoenergetic and isoproteic. The diet was prepared according to the macronutrient composition of the standard diet Labina ${ }^{\circledR}$. Ash, fibre and moisture represent the total volume of the product. Glutamine $(500 \mathrm{mg} / \mathrm{kg}$ per d) or glutamine plus L-NAME $(500 \mathrm{mg} / \mathrm{kg}$ per d plus $10 \mathrm{mg} / \mathrm{kg}$ per d) was given daily, for $7 \mathrm{~d}$ by oral administration, to the GLN or GLN/LN groups, respectively. 
$1 \mathrm{ml}$ of a stannous chloride solution $(580 \mathrm{~mm}, \mathrm{pH} 7 \cdot 0)$ at $37^{\circ} \mathrm{C}$ for $10 \mathrm{~min}$. After incubation, $37 \cdot 0-55 \cdot 5 \mathrm{MBq}$ of ${ }^{99 \mathrm{~m}} \mathrm{Tc}$, which was eluted from a ${ }^{99}$ Molybdenum $/{ }^{99 \mathrm{~m}}$ Technetium (IPEN) generator as sodium pertechnetate, were added, and the preparation was incubated at $37^{\circ} \mathrm{C}$ for $10 \mathrm{~min}$. The tubes containing the preparation were then centrifuged at $3000 \mathrm{~g}$ for $25 \mathrm{~min}$, and this procedure was repeated three times. During the final procedure, the radioactivity of the supernatant and precipitate was measured using a dose calibrator (Capintec $\mathrm{CRC}^{\circledR}-15 \mathrm{R}$ Dose Calibrator; CAPINTEC, Inc.), and the percentage of ${ }^{99} \mathrm{~m}$ Tc incorporated into the bacterial cells was determined using the following equation ${ }^{(21)}$ :

$\%$ Labelled bacteria

$$
=\frac{\text { cpm of precipitate }}{\text { cpm of precipitate }+ \text { cpm of supernatant }} \times 100 \text {. }
$$

\section{Bacterial translocation study}

On the eighth day after the above-described treatment, the mice were orally administered $0.1 \mathrm{ml}(1.85 \mathrm{MBq})$ of ${ }^{99 \mathrm{~m}} \mathrm{Tc}-E$. coli at $10^{8}$ colony-forming units. The surgical procedure was performed on mice $90 \mathrm{~min}$ after the administration of ${ }^{99 \mathrm{~m}} \mathrm{Tc}-E$. coli, and $18 \mathrm{~h}$ later, the animals were anaesthetised and euthanised. The blood, mesenteric lymph nodes, liver, spleen and lungs were collected, weighed and placed into tubes to determine their radioactivity. The samples were assessed using a counter with a NaI (Tl) crystal (ANSR-Abbott). The results are expressed as counts per min $(\mathrm{cpm}) / \mathrm{g}$ of tissue ${ }^{(17,18,20)}$.

\section{Intestinal permeability study}

Another set of mice were orally administered $0.1 \mathrm{ml}$ of 18.5 MBq diethylenetriaminepentaacetate ( $\left.{ }^{99 \mathrm{~m}} \mathrm{Tc}-\mathrm{DTPA}\right)$. A

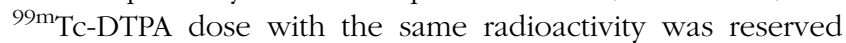
and used as a standard to correct for the physical decay of ${ }^{99 \mathrm{~m}} \mathrm{Tc}$. For the measurement of radioactivity, $90 \mathrm{~min}$ after the administration of ${ }^{99 \mathrm{~m}} \mathrm{Tc}$-DTPA, sixty mice were divided into four groups of fifteen mice and were separately assessed at different time points (4,8 and $18 \mathrm{~h}$ ). The mice underwent the aforementioned surgical procedure. Following the operation, the mice were anaesthetised and euthanised, and $500 \mu \mathrm{l}$ of blood were collected to measure radioactivity. The data are expressed as the percentage of dose using the following equation ${ }^{(18,22)}$ :

$$
\% \text { Dose } / \text { blood }=\frac{\text { cpm in blood }}{\text { cpm of standard }} \times 100 .
$$

\section{Ileal histological analysis}

Samples of the small intestine were collected for histological analysis $18 \mathrm{~h}$ after surgery. A $1 \mathrm{~cm}$ ring of the distal ileum adjacent to the intestinal obstruction was resected, fixed in a $4 \%$ buffered formalin solution, dehydrated, cleared, embedded in paraffin, cut into 4 to $5 \mathrm{~mm}$-thick sections, stained with haematoxylin and eosin, coded and qualitatively analysed using optical microscopy performed by a single pathologist who was unaware of the experimental conditions for each group $^{(22,23)}$. The determination of villus height was done using five villus samples obtained from the images of five fields obtained from the histological sections of at least three mice in each group and represented as the average height of villi.

\section{Serum IL-10 and interferon- $\gamma$ concentration determination}

As has been described previously, $18 \mathrm{~h}$ after the intestinal obstruction, blood was collected from the axillary plexus. The blood was centrifuged at $1000 \mathrm{~g}$ for $10 \mathrm{~min}$, and serum was separated and stored at $-70^{\circ} \mathrm{C}$ until the assay was performed. The concentrations of IL-10 and interferon- $\gamma$ (IFN- $\gamma$ ) were measured with ELISA using commercially available antibodies in accordance with the manufacturer's instructions (BioSource International, Inc.) $^{(24)}$.

\section{Intestinal secretory Ig type A concentration determination}

As has been described above, four groups of five mice were treated. The levels of secretory Ig type A (sIgA) were measured in the intestinal fluid as described previously ${ }^{(25)}$. After euthanasia, the small intestines were removed from the mice of each group, and the contents were separated, weighed and suspended in PBS using $500 \mathrm{mg}$ of the intestinal contents per $2 \mathrm{ml}$ of PBS supplemented with an anti-protease cocktail ( $1 \mu \mathrm{M}$-aprotinin, $25 \mu \mathrm{M}$-leupeptin, $1 \mu \mathrm{M}$-pepstatin and $1 \mathrm{~mm}$-phenylmethanesulfonyl fluoride). After $30 \mathrm{~min}$ of centrifugation at $2000 \mathrm{~g}$ at $4^{\circ} \mathrm{C}$, the supernatant was collected and frozen at $-70^{\circ} \mathrm{C}$ until use. Ig levels in the intestinal fluid were evaluated with ELISA using goat anti-mouse IgA (Sigma Chemical Company) and horseradish peroxidaseconjugated goat anti-mouse IgA (Sigma). The colour was developed using $O$-phenylenediamine (Sigma), and the absorbance at $492 \mathrm{~nm}$ was determined using an ELISA plate reader (Bio-Rad Laboratories). Ig concentrations were determined using a purified mouse IgA standard (Southern Biotechnology Associates, Inc. $)^{(23,26)}$.

\section{Statistical analysis}

The results were evaluated using the Kolmogorov-Smirnov test for normality and a box plot for outliers. Data with normal distributions were tested using a one-way ANOVA and the Tukey post hoc test or a two-way ANOVA and the Bonferroni post hoc test, whereas non-parametric data were tested using a Kruskal-Wallis ANOVA and Dunn's test. $P$ values less than 0.05 were considered significant. The analysis was performed using the GraphPad Prism 5 program.

\section{Results}

\section{Effects of nitric oxide synthase inhibition on bacterial translocation}

The administration of L-NAME with glutamine increased the BT to levels that were significantly higher than those of the 
Table 2. Biodistribution of ${ }^{99 \mathrm{~m}} \mathrm{Tc}$-Escherichia coli (counts per $\mathrm{min} / \mathrm{g}$ )

(Medians with their 25th and 75th interquartile ranges (IQR))

\begin{tabular}{|c|c|c|c|c|c|c|c|c|}
\hline \multirow[b]{2}{*}{ Organs/blood } & \multicolumn{2}{|c|}{ Sham } & \multicolumn{2}{|r|}{10} & \multicolumn{2}{|c|}{ GLN } & \multicolumn{2}{|c|}{ GLN/LN } \\
\hline & Median & IQR & Median & IQR & Median & IQR & Median & IQR \\
\hline MLN & $166 \cdot 66^{a}$ & $43 \cdot 67-816 \cdot 70$ & $1966 \cdot 66^{b}$ & $1125-2633$ & $287.50^{\mathrm{a}}$ & $33 \cdot 33-558 \cdot 30$ & $1150 \cdot 00^{\mathrm{b}}$ & $950 \cdot 00-1680 \cdot 00$ \\
\hline Blood & $60 \cdot 36^{a}$ & $40 \cdot 71-62 \cdot 82$ & $462.50^{\mathrm{b}}$ & $189 \cdot 4-576 \cdot 2$ & $122 \cdot 59^{a}$ & $24 \cdot 36-331 \cdot 90$ & $1031.46^{\mathrm{C}}$ & $429.50-2339.00$ \\
\hline Liver & $334 \cdot 10^{a}$ & $145 \cdot 50-551 \cdot 70$ & $1226 \cdot 51^{\mathrm{b}}$ & 1049-2062 & $746 \cdot 22^{a}$ & $377 \cdot 40-924 \cdot 30$ & $2464 \cdot 94^{c}$ & $1831.00-5482.00$ \\
\hline Lungs & $81 \cdot 25^{\mathrm{a}}$ & $8.00-262.50$ & $587.50^{\mathrm{b}}$ & $490 \cdot 00-760 \cdot 00$ & $144.44^{\mathrm{a}}$ & $46.01-268.90$ & $1057 \cdot 14^{\mathrm{b}}$ & $435.00-1529.00$ \\
\hline Spleen & $77 \cdot 77^{\mathrm{a}}$ & $23.00-390 \cdot 90$ & $1300 \cdot 00^{b}$ & $272 \cdot 70-1613 \cdot 00$ & $163 \cdot 33^{a}$ & $47 \cdot 86-191 \cdot 70$ & $966 \cdot 66^{\mathrm{b}}$ & $300.00-1163.00$ \\
\hline
\end{tabular}

Sham, simulated group receiving a standard diet; $\mathrm{IO}$, intestinal obstruction group receiving a standard diet; GLN, intestinal obstruction group receiving glutamine by oral administration and a specially prepared diet; GLN/LN, intestinal obstruction group receiving glutamine plus NG-nitro-L-arginine methyl ester (L-NAME) by oral administration and a specially prepared diet; MLN, mesenteric lymph nodes.

a,b,c Median values with unlike superscript letters were significantly different between the groups $(P<0.05)$. Simultaneous comparison was done among the different treatment groups ( $n 7$ per group).

sham and GLN groups ( $P<0.05$; Table 2$)$. Moreover, compared with that in the IO group, BT was higher in the blood and livers of the GLN/LN group and similar to that in the other investigated organs.

\section{Effects of nitric oxide synthase inhibition on intestinal permeability}

The uptake of ${ }^{99 \mathrm{~m}_{\mathrm{T}}}$ Tc-DTPA in the blood of the IO group mice was significantly higher than that of the sham group at each investigated time point and reached a maximum at $18 \mathrm{~h}$ (Fig. 1). Glutamine pretreatment $(500 \mathrm{mg} / \mathrm{kg}$ per d) reduced intestinal permeability to physiological levels (i.e. those of the sham group). NO synthase inhibition by L-NAME did not alter intestinal permeability at the investigated time points.

\section{Effects of nitric oxide synthase inhibition on the distal ileum mucosal morphology}

In the sham group (Fig. 2(A)), normal ileal architecture was observed. These findings are in contrast with the marked histological damage to the ileum produced by intestinal obstruction (Fig. 2(B)). There was intense swelling of the lamina propria and damage to the villi, which were dramatically shortened. Leucocyte infiltration and lymphatic dilation were focally present in the lamina propria. The glutaminepretreated mice exhibited partially preserved intestinal structures; the continuity of the epithelium and the caliciform cells was preserved, and the lamina propria displayed discrete oedema (Fig. 2(C)). In the NO synthase inhibition group, GLN/LN, the ileal mucosa and the overall structure were preserved, similar to those of the sham group (Fig. 2(D)).

We determined the average villus height (Fig. 3). The sham, GLN and GLN/LN groups presented similar average villus heights, confirming the results of our qualitative histological analysis. The IO group presented an intense and significant reduction in villus height, indicating the degree of intestinal damage.

\section{Effects of nitric oxide synthase inhibition on the local immune response}

Similar sIgA levels were observed in the sham and IO groups $(P>0.05)$ (Fig. 4). In contrast, the glutamine-pretreated mice had higher levels of SIgA $(P<0.05)$. NO synthase inhibition caused by L-NAME treatment did not change the IgA levels compared with those of the GLN group $(P>0.05)$.

\section{Effects of nitric oxide synthase inhibition on the systemic immune response}

The mice in the IO group had higher levels of IFN- $\gamma$ than those in the sham group $(P<0.05)$, but IL-10 levels were similar between the two groups $(P>0.05)$. In contrast, the GLN group had higher IFN- $\gamma$ and IL-10 levels than the sham and IO groups (Fig. 5). The mice in the GLN/LN group had IFN- $\gamma$ levels similar to those of the IO group $(P>0.05)$, but their IL-10 levels were as high as those of the GLN group. The ratios of the inflammatory to anti-inflammatory cytokines were $3.82,3.24,1.29$ and 0.61 in the IO, sham, GLN and GLN/LN groups, respectively.

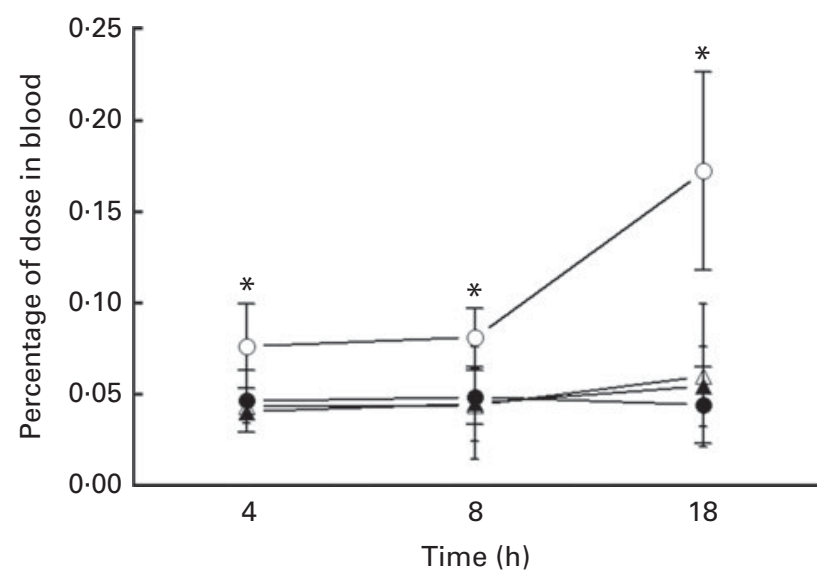

Fig. 1. Intestinal permeability of mice in the sham group receiving a standard diet $(\bullet)$, the IO group with intestinal obstruction receiving a standard diet $(O)$, the GLN group with intestinal obstruction receiving glutamine by oral administration and a specially prepared diet $(\Delta)$ and the GLN/LN group with intestinal obstruction receiving glutamine plus NG-nitro-L-arginine methyl ester (L-NAME) by oral administration and a specially prepared diet $(\mathbf{\Lambda})$ ( $n 5$ per group). Values are means, with standard deviations represented by vertical bars. ${ }^{*}$ Mean values were significantly different from those of the other groups $(P<0.05)$. \% dose $=(($ counts $/ \mathrm{min}(\mathrm{cpm})$ in blood $\times 100) / \mathrm{cpm}$ of the administered dose). 


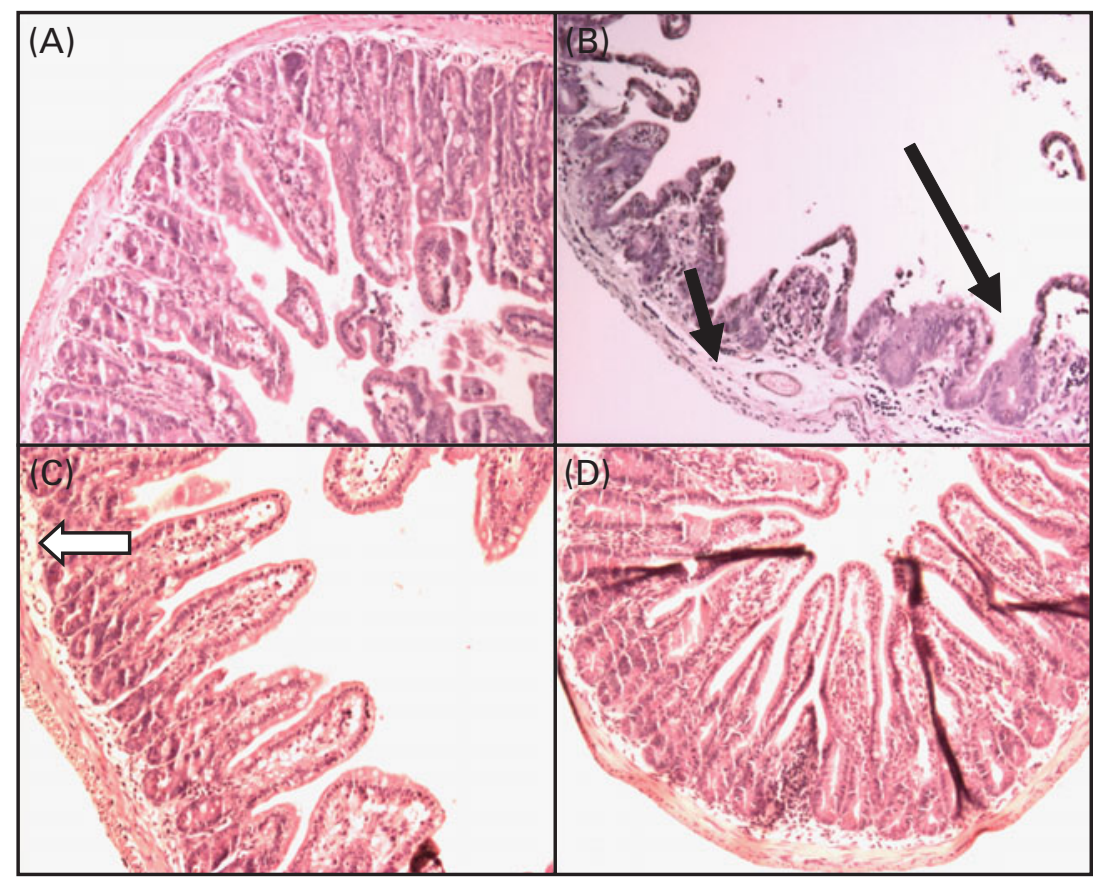

Fig. 2. Alterations in the structure of mucous membrane of the ileum under microscopy in (A) the sham group (simulated group receiving the standard diet) presenting a normal structure of the ileal mucosa; (B) the IO group (intestinal obstruction group receiving a standard diet) with representative aspects of ileal mucosa showing evident damage of ileal architecture, villus swelling and shortening and intense swelling in the lamina propria $(\leftarrow)$, associated with the infiltration of leucocytes $(\longleftarrow)$ and the dilatation of lymphatic ducts, and villi are more sparse and enlarged $(\longleftarrow)$ than those in the sham group; (C) the GLN group (intestinal obstruction group receiving glutamine by oral administration and a specially prepared diet) showing evident protection of mucosa structure indicated by the absence of oedema and the preservation of villus structure despite persistence of a few enlarged villi $(\Longleftrightarrow)$; and (D) the GLN/LN group (intestinal obstruction group receiving glutamine plus NG-nitro-L-arginine methyl ester (L-NAME) by oral administration and a specially prepared diet) presenting the preservation of ileal mucosa structural aspects, very similar to the sham group. (A colour version of this figure can be found online at http://www.journals.cambridge.org/bjn).

\section{Discussion}

The present study assessed the influence of NO synthase inhibition on the glutamine pathway and associated processes, such as the immunological response and intestinal permeability, in a murine model of BT. We had previously demonstrated that pre-injury glutamine administration reduced BT to physiological levels ${ }^{(18)}$; however, the mechanism was not investigated. It is possible that among the multiple functions of glutamine, glutamate generation via glutaminase might be a metabolic pathway of NO production ${ }^{(27)}$. The present results demonstrated that the non-selective NO synthase inhibition caused by L-NAME administration (GLN/LN group) increased BT to all the investigated organs compared with that in the sham and GLN groups and only to the blood and liver compared with that in the IO group. These data can be explained by the potent bactericidal action of $\mathrm{NO}$ against micro-organisms, including the majority of the intestinal microbiota ${ }^{(28)}$. Another mechanism that may be associated with BT is intestinal barrier integrity. However, one interesting finding of the present study was that NO synthase inhibition did not alter intestinal permeability. The reduction in intestinal permeability caused by glutamine was probably mediated by another mechanism, such as an increase in heat shock protein (HSP) production. HSP are highly conserved proteins that are found in all cells and are fundamental to the responses of cells and tissues to stress and injury. HSP induction prevented any endotoxininduced intestinal mucosal atrophy or increases in intestinal permeability ${ }^{(29)}$. Wischmeyer et al. ${ }^{(30)}$ and Musch et al. ${ }^{(31)}$ showed that glutamine enhanced HSP-70 expression in intestinal epithelial cells, which correlated with improved cell survival following oxidant stress, and that the glutamine protection was abrogated when HSP-70 expression was inhibited. Other aspects could be considered such as the role of glutathione as an antioxidant agent protecting the intestinal mucosa against oxidative stress and inhibiting apoptosis ${ }^{(32-34)}$ as well as the

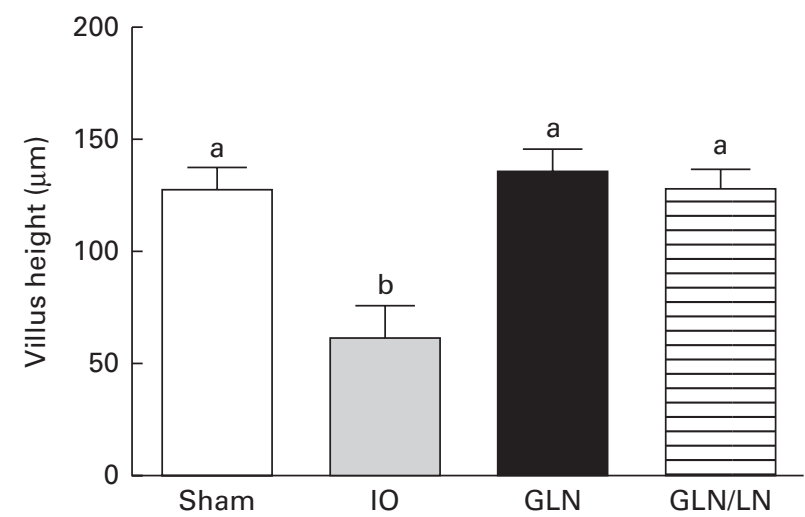

Fig. 3. Determination of the villus height in the sham group receiving a standard diet, the $1 \mathrm{O}$ group with intestinal obstruction receiving a standard diet, the GLN group with intestinal obstruction receiving glutamine by oral administration and the GLN/LN group with intestinal obstruction receiving glutamine plus NG-nitro-L-arginine methyl ester (L-NAME) by oral administration. The last two groups received a specially prepared diet. Values are means, with standard deviations represented by vertical bars. ${ }^{a, b}$ Mean values with unlike letters were significantly different between the groups $(P<0.05)$. 


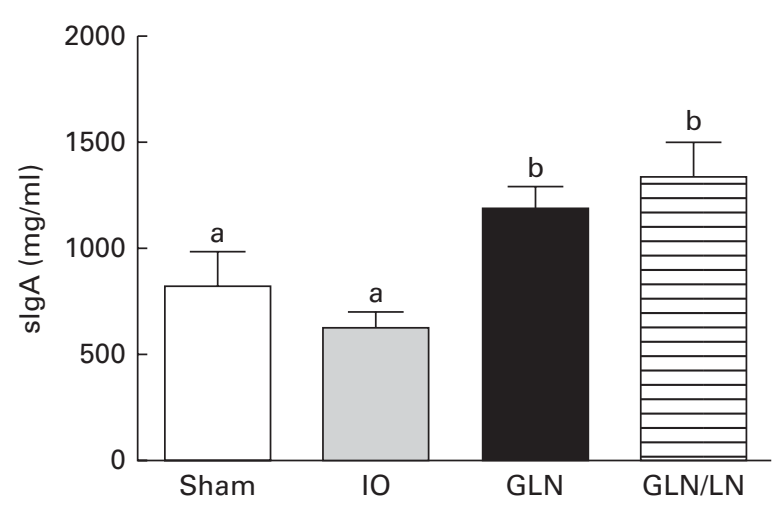

Fig. 4. Secretory $\lg A(\operatorname{sg} A)$ levels in the sham group receiving a standard diet, the $1 \mathrm{O}$ group with intestinal obstruction receiving a standard diet, the GLN group with intestinal obstruction receiving glutamine by oral administration and a specially prepared diet and the GLN/LN group with intestinal obstruction receiving glutamine plus NG-nitro-L-arginine methyl ester (L-NAME) by oral administration and a specially prepared diet ( $n 5$ per group). Values are means, with standard deviations represented by vertical bars. ${ }^{a, b}$ Mean values with unlike letters were significantly different between the groups $(P<0.05)$.

regulatory action of protein metabolism. The latter acts mainly on tight junctions having a protector effect on the intestinal barrier $^{(35)}$.

Immunological responses are also an important part in the BT process. In the present study, IFN- $\gamma$ levels were higher in the IO group than in the sham group $(P>0.05)$. In addition, the levels of this cytokine were higher in the GLN group than in the other groups $(P<0 \cdot 05)$. These results are similar to the observations of Yeh et al. ${ }^{(35)}$ and Horio et al. ${ }^{(36)}$, who demonstrated that glutamine enhanced IFN- $\gamma$ levels in an animal model of septic shock and in active macrophages. Pro-inflammatory mediators enhance cell-mediated immunity, and their role in host defence is well known, although excessive, uncontrolled inflammation produces a variety of pathological conditions. This process is controlled by a balance between pro-inflammatory and regulatory responses ${ }^{(37,38)}$. In contrast, NO synthase inhibition modified the impact of glutamine by generating levels of IFN- $\gamma$ similar to those observed in the IO group $(P>0.05)$. The lower IFN- $\gamma$ levels were probably responsible for the increased BT observed in the GLN/LN group because the protective effect of IFN- $\boldsymbol{\gamma}$ on BT may be related to NO production, up-regulated phagocyte levels and, subsequently, increased microbe ingestion ${ }^{(39)}$. Furthermore, inducible NO is essential for killing certain bacteria and is potentially important for regulating the proliferation and differentiation of $\mathrm{T}$ cells ${ }^{(15)}$. Under normal circumstances, the translocating bacteria are phagocytosed before reaching the mesenteric lymph nodes. The assumption is that if the host is immunocompromised, then the normal defence mechanisms fail and bacteria can translocate to and survive at distant extraintestinal sites, which then leads to increased inflammation $^{(40)}$

To control this exacerbated systemic inflammation, the production of anti-inflammatory cytokines, particularly IL-10, contributes to the down-regulation of pro-inflammatory cytokines. The present results showed that blood IL-10 concentrations were similar in the sham and IO groups
$(P>0.05)$ and elevated in the GLN and GLN/LN groups, which were similar to each other. However, when the cytokine ratio (which is important due to their opposing relationships) was considered instead of the absolute values, the IFN- $\gamma:$ IL-10 ratio was the highest in the IO group (3.82), followed by the sham (3.24), GLN (1.29) and GLN/LN (0.61) groups. These results show that glutamine increased IFN- $\gamma$ levels while further increasing IL-10 levels, which probably contributed to the beneficial effects of this immunonutrient on BT and intestinal permeability. Similar results were reported by Boelens et $a .^{(41)}$ and Oliveira et al. ${ }^{(42)}$, who showed increases in IFN- $\gamma$ (a Th1 cytokine), IL- 4 (a Th2 cytokine) and IL-10 levels after glutamine treatment in trauma patients and septic animals, respectively. Wang et al. ${ }^{(43)}$ showed that sepsis increased mucosal permeability, which was then reduced by the heat shock response, and that increases in IL-10 levels may be involved in the protective effects of the HSP. However, the lowest IFN:IL-10 ratio in the present study was observed in the GLN/LN group and was caused by the decreased levels of IFN- $\gamma$ in this group. This observation may lead to the conclusion that inflammation is necessary to counter BT. IL-10 induction and NO synthase inhibition presumably have a suppressive effect on the pro-inflammatory response, which profoundly affects the bactericidal activity in phagocytic cells and facilitates the intracellular survival of pathogens ${ }^{(39,44)}$. In addition, IL-10 is responsible for humoral immunity and, consequently, the levels of IgA, which acts by binding to the bacteria or pathogens. Thus, this activity of IgA prevents bacterial internalisation, which is the first step of $\mathrm{BT}^{(45)}$. In the present study, sIgA levels were enhanced in the GLN group than in the sham and IO groups $(P<0.05)$. Similar results have been obtained by Kudsk et $a l .{ }^{(46)}$, Fukatsu et $a l^{(47)}$ and Jiang et $a l .{ }^{(48)}$. As an unexpected result, the sIgA levels of the GLN/LN group were similar to those of the GLN group; however, elevated BT was only observed in the former group. The absence of

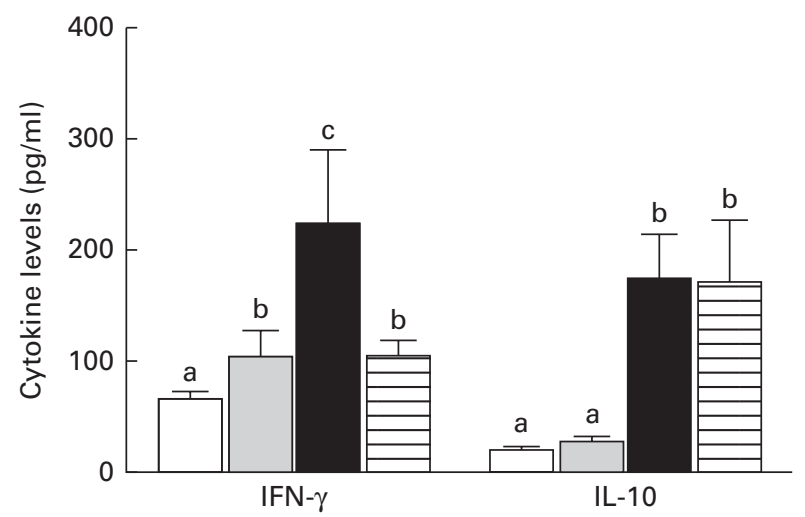

Fig. 5. Serum levels of interferon- $\gamma(\mathrm{IFN}-\gamma)$ and $\mathrm{IL}-10$ in the sham group receiving a standard diet $(\square)$, the IO group with intestinal obstruction receiving a standard diet $(\square)$, the GLN group with intestinal obstruction receiving glutamine by oral administration $(\square)$ and the GLN/LN group with intestinal obstruction and receiving glutamine plus NG-nitro-L-arginine methyl ester (L-NAME) by oral administration (曰). The last two groups received a specially prepared diet ( $n 5$ per group). Values are means, with standard deviations represented by vertical bars. ${ }^{a, b, c}$ Mean values with unlike letters were significantly different between the groups $(P<0.05)$. 
NO probably contributed to the increased BT through other pathways that are independent of sIgA. This result reinforces the notion that IFN- $\gamma$ and NO play crucial roles in host defence mechanisms via their antimicrobial activity ${ }^{(49)}$. Moreover, the intestinal barrier function can be affected without the disruption of tight junctions; however, the transepithelial resistance is reduced, which increases the flow of small molecules, but not of large molecules, such as DTPA ${ }^{(50,51)}$.

In conclusion, the present results indicate that the effects of glutamine on BT involve NO activity, which interferes with the pro-inflammatory systemic immunological response, although the protection of intestinal permeability by glutamine is independent of NO. Further studies are necessary to determine which NO isoform is triggered by glutamine and to assess the cytokine response in the intestinal lamina propria.

\section{Acknowledgements}

The authors are grateful to the following sources for providing support: Pró-Reitoria de Pesquisa da Universidade Federal de Minas Gerais (PRPq); CNPq (the National Council of Technological and Scientific Development); CAPES (the Coordination for the Improvement of Higher Education Personnel); FAPEMIG (the Minas Gerais State Foundation for Research Support). R. G. C. S. designed and conducted the research, analysed the data and helped draft the manuscript. I. E. P. Q., M. L. V. and S. V. G. helped conduct the research. J. R. N. and F. S. M. assisted in the SIgA concentration determination. R. M. E. A. helped conduct the histological analysis. J. A. N.-M. provided assistance with the cytokine ELISA. M. I. T. D. C. and V. N. C. supervised the research and helped draft the manuscript. All the authors read and approved the final manuscript. The authors declare that they have no conflicts of interest.

\section{References}

1. Zheng YM, Li F, Zhang MM, et al. (2006) Glutamine dipeptide for parenteral nutrition in abdominal surgery: a meta-analysis of randomized controlled trials. World $J$ Gastroenterol 12, 7537-7541.

2. Rhoads JM, Argenzio RA, Chen W, et al. (1997) L-Glutamine stimulates intestinal cell proliferation and activates mitogenactivated protein kinases. Am J Physiol 272, 943-953.

3. Curi R, Lagranha CJ, Doi SQ, et al. (2005) Molecular mechanisms of glutamine action. J Cell Physiol 204, 392-401.

4. Carr EL, Kelman A, Wu GS, et al. (2010) Glutamine uptake and metabolism are coordinately regulated by ERK/MAPK during T lymphocyte activation. J Immunol 185, 1037-1044.

5. Wiest R \& Rath HC (2003) Bacterial translocation in the gut. Best Pract Res Clin Gastroenterol 17, 397-425.

6. Zanoni FL, Benabou S, Greco KV, et al. (2009) Mesenteric microcirculatory dysfunctions and translocation of indigenous bacteria in a rat model of strangulated small bowel obstruction. Clinics 64, 911-919.

7. Shiomi H, Shimizu T, Endo Y, et al. (2007) Relations among circulating monocytes, dendritic cells, and bacterial translocation in patients with intestinal obstruction. World J Surg 31, 1806-1812.

8. Lotz M, König T, Ménard S, et al. (2007) Cytokine-mediated control of lipopolysaccharide-induced activation of small intestinal epithelial cells. Immunology 122, 306-315.
9. Amin PB, Diebel LN \& Liberati DM (2008) Secretory immunoglobulin A blunts gut-mediated priming of neutrophils in vitro. J Trauma 64, 1437-1442.

10. Sanjabi S, Zenewicz LA, Kamanaka M, et al. (2009) Antiinflammatory and pro-inflammatory roles of TGF- $\beta$, IL-10, and IL-22 in immunity and autoimmunity. Curr Opin Pharmacol 9, 447-453.

11. Ding LA \& Li JS (2003) Effects of glutamine on intestinal permeability and bacterial translocation in TPN-rats with endotoxemia. World J Gastroenterol 9, 1327-1332.

12. Wu G \& Meininger CJ (2002) Regulation of nitric oxide synthesis by dietary factors. Annu Rev Nutr 22, 61-86.

13. Barocelli E, Ballabeni V, Ghizzardi P, et al. (2006) The selective inhibition of inducible nitric oxide synthase prevents intestinal ischemia-reperfusion injury in mice. Nitric Oxide 14, 212-218.

14. Aktan F (2004) iNOS mediated nitric oxide production and its regulation. Life Sci 75, 639-653.

15. Kubes P (2000) Inducible nitric oxide synthase: a little bit of good in all of us. Gut 47, 6-9.

16. Naito Y, Takagi T, Ichikawa H, et al. (2004) A novel potent inhibitor of inducible nitric oxide inhibitor, ONO-1714, reduces intestinal ischemia-reperfusion injury in rats. Nitric Oxide 10, 170-177.

17. de Oliveira MA, Lemos DS, Diniz SO, et al. (2006) Prevention of bacterial translocation using glutamine: a new strategy of investigation. Nutrition 22, 419-424.

18. dos Santos RG, Viana ML, Generoso SV, et al. (2010) Glutamine supplementation decreases intestinal permeability and preserves gut mucosa integrity in an experimental mouse model. J Parenter Enteral Nutr 34, 408-413.

19. Salvalaggio PR, Neto CZ, Tolazzi AR, et al. (2002) Oral glutamine does not prevent bacterial translocation in rats subjected to intestinal obstruction and Escherichia coli challenge but reduces systemic bacteria spread. Nutrition 18, 334-337.

20. Quirino IE, Correia MI \& Cardoso VN (2007) The impact of arginine on bacterial translocation in an intestinal obstruction model in rats. Clin Nutr 26, 335-340.

21. Diniz SO, Resende BM, Nunan EA, et al. (1999) ${ }^{99 \mathrm{~m}}$ Technetium labelled Escherichia coli. Appl Radiat Isot 51, 33-36.

22. Viana ML, Santos RG, Generoso SV, et al. (2010) Pretreatment with arginine preserves intestinal barrier integrity and reduces bacterial translocation in mice. Nutrition $\mathbf{2 6}$ 218-223.

23. Generoso SV, Viana M, Santos R, et al. (2010) Saccharomyces cerevisiae strain UFMG 905 protects against bacterial translocation, preserves gut barrier integrity and stimulates the immune system in a murine intestinal obstruction model. Arch Microbiol 192, 477-484.

24. Generoso SV, Viana ML, Santos RG, et al. (2011) Protection against increased intestinal permeability and bacterial translocation induced by intestinal obstruction in mice treated with viable and heat-killed Saccharomyces boulardii. Eur J Nutr 50, 261-269.

25. Martins FS, Silva AA, Vieira AT, et al. (2009) Comparative study of Bifidobacterium animalis, Escherichia coli, Lactobacillus casei and Saccharomyces boulardii probiotic properties. Arch Microbiol 191, 623-630.

26. Rodrigues AC, Cara DC, Fretez SH, et al. (2000) Saccharomyces boulardii stimulates sIgA production and the phagocytic system of gnotobiotic mice. J Appl Microbiol 89, 404-414.

27. van de Poll MC, Ligthart-Melis GC, Boelens PG, et al. (2007) Intestinal and hepatic metabolism of glutamine and citrulline in humans. $J$ Physiol 581, 819-827. 
28. Han X, Fink MP \& Delude R (2003) Proinflammatory cytokines cause $\mathrm{NO}^{*}$-dependent and -independent changes in expression and localization of tight junction proteins in intestinal epithelial cells. Shock 19, 229-237.

29. Wang Q \& Hasselgren PO (2002) Heat shock response reduces intestinal permeability in septic mice: potential role of interleukin-10. Am J Physiol Regul Integr Comp Physiol 282, 669-676.

30. Wischmeyer PE, Musch MW, Madonna MB, et al. (1997) Glutamine protects intestinal epithelial cells: role of inducible HSP70. Am J Physiol 272, 879-884.

31. Musch MW, Hayden D, Sugi K, et al. (1998) Cell-specific induction of hsp72-mediated protection by glutamine against oxidant injury in IEC18 cells. Proc Assoc Am Physicians 110, 136-139.

32. Perricone C, Carolis C \& Perricone R (2009) Glutathione: a key player in autoimmunity. Autoimmun Rev 8, 697-701.

33. Zhou X, Wu X, Yin Y, et al. (2012) Preventive oral supplementation with glutamine and arginine has beneficial effects on the intestinal mucosa and inflammatory cytokines in endotoxemic rats. Amino Acids 43, 813-821.

34. Ban K \& Kozar RA (2010) Glutamine protects against apoptosis via downregulation of $\mathrm{Sp} 3$ in intestinal epithelial cells. Am J Physiol Gastrointest Liver Physiol 299, 1344-1353.

35. Yeh CL, Hsu CS, Yeh SL, et al. (2005) Dietary glutamine supplementation modulates Th1/Th2 cytokine and interleukin-6 expressions in septic mice. Cytokine 31, 329-334.

36. Horio Y, Osawa S, Takagaki K, et al. (2008) Glutamine supplementation increases Th1-cytokine responses in murine intestinal intraepithelial lymphocytes. Cytokine 44, 92-95.

37. Dinarello CA (2000) Proinflammatory cytokines. Chest 118, 503-508.

38. Rakoff-Nahoum S, Paglino J, Eslami-Varzaneh F, et al. (2004) Recognition of commensal microflora by toll-like receptors is required for intestinal homeostasis. Cell 118, 229-241.

39. Naderi beni F, Fattahi F, Mirshafiey A, et al. (2012) Increased production of nitric oxide by neutrophils from patients with chronic granulomatous disease on interferon-gamma treatment. Int Immunopharmacol 12, 689-693.

40. MacFie J (2004) Current status of bacterial translocation as a cause of surgical sepsis. Br Med Bull 71, 1-11.
41. Boelens PG, Houdijk AP, Fonk JC, et al. (2004) Glutamineenriched enteral nutrition increases in vitro interferongamma production but does not influence the in vivo specific antibody response to KLH after severe trauma. A prospective, double blind, randomized clinical study. Clin Nutr 23, 391-400.

42. Oliveira GP, Oliveira MB, Santos RS, et al. (2009) Intravenous glutamine decreases lung and distal organ injury in an experimental model of abdominal sepsis. Crit Care 13, R74.

43. Wang Q, Fang $\mathrm{CH}$ \& Hasselgren PO (2001) Intestinal permeability is reduced and IL-10 levels are increased in septic IL-6 knockout mice. Am J Physiol Regul Integr Comp Physiol 281, R1013-R1023.

44. Redpath S, Ghazal P \& Gascoigne NR (2001) Hijacking and exploitation of IL-10 by intracellular pathogens. Trends Microbiol 9, 86-92.

45. Kudsk KA (2008) Glutamine: more evidence, more promise. J Parenter Enteral Nutr 32, 492-494.

46. Kudsk KA, Wu Y, Fukatsu K, et al. (2000) Glutamineenriched total parenteral nutrition maintains intestinal interleukin-4 and mucosal immunoglobulin A levels. J Parenter Enteral Nutr 24, 270-275.

47. Fukatsu K, Kudsk KA, Zarzaur BL, et al. (2001) TPN decreases $I L-4$ and $I L-1 O$ mRNA expression in lipopolysaccharide stimulated intestinal lamina propria cells but glutamine supplementation preserves the expression. Shock 15, 318-322.

48. Jiang JW, Ren ZG, Chen LY, et al. (2011) Enteral supplementation with glycyl-glutamine improves intestinal barrier function after liver transplantation in rats. Hepatobiliary Pancreat Dis Int 10, 380-385.

49. Akaike T, Okamoto T, Zaki MH, et al. (2009) New paradigm of host defense against intracellular pathogens by nitric oxide. Nibon Hansenbyo Gakkai Zasshi 78, 41-47.

50. Abreu MT, Palladino AA, Arnold ET, et al. (2000) Modulation of barrier function during Fas-mediated apoptosis in human intestinal epithelial cells. Gastroenterology 119, $1524-1536$

51. Arrieta MC, Bistritz L \& Meddings JB (2006) Alterations in intestinal permeability. Gut 55, 1512-1520. 